\title{
Surgical management of perineal laceration in mares
}

\begin{abstract}
Perineal laceration is a common complication during foaling in mares. The forefeet of the foal may catch on the dorsal aspect of the vagino-vestibular junction and violent straining by the mare during foaling may cause laceration of the vaginal wall, rectum and the surrounding perineum. If this posture of the foal is corrected well in time by manual assistance than the condition can be averted. If correction is partial than the condition can be formation of rectovaginal fistula. If correction is not done well in time than expulsive effort of foaling may cause laceration of rectum, vagina and surrounding structures i.e. perineum. The laceration of perineum can be small, moderate to extensive. The small and moderate perineal laceration can be managed in easier manner as compared to extensive laceration. In these cases the laceration was extensive and difficult to manage. Such types of cases require immediate attention.
\end{abstract}

Volume 4 Issue 4 - 2017

\author{
Prem Singh, Sandeep Saharan \\ Department of Veterinary Surgery and Radiology, Lala Lajpat Rai \\ University of Veterinary and Animal Sciences, India
}

Correspondence: Prem Singh, Department of Veterinary Surgery and Radiology, Lala Lajpat Rai University of Veterinary and Animal Sciences, Hisar-1 25004, Haryana, India,

Email pswatch05@yahoo.co.in

Received: October 27, 2016 | Published: June 28, 2017

\section{Materials \& methods}

Study was conducted on five mares between ages of 5-8years. The mares were brought to the Teaching Veterinary Clinical Complex with the history of laceration of perineum after foaling. The mares were passing faecal balls through the vagina. Entire perineal area was swollen. According to the owner the foaling was difficult and they could not get sufficient time to correct the posture of the foal and the mares expelled the foals without any external assistance. When they observed mare after foaling then perineal area was teared and swollen but the foal was normal. When the mare were examined in Teaching Veterinary Clinical Complex than it was observed that ventral wall of the rectum and dorsum of the vagina were observed to be completely teared and there was common passage for both defecation and urination (Figure 1). The mares were straining for defecation and urination. There was problem of air sucking during straining.

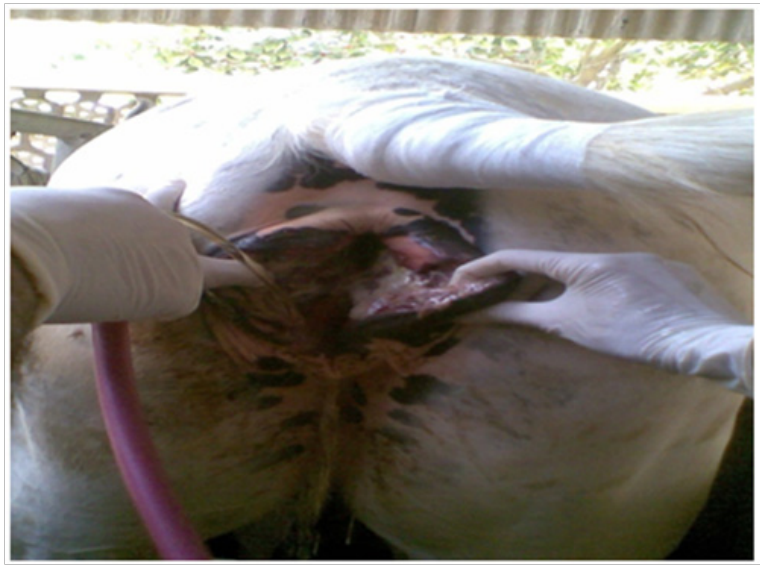

Figure I Showing extensive tearing of rectum and vagina.

The mare was administered tetanus toxoid along with antibiotics, anti-histaminics, anti-inflammatory, vitamin- C \& B-complex. The contaminated and swollen perineal area was cleaned with light povidone-iodine solution. Before repair of the lacerated perineum, the treatment of antibiotics, anti-histaminics, anti-inflammatory, vitamin-
C \& B-complex along with application of diluted povidone iodine (1:10) was followed for ten days. The owner of the mares was advised to bring the mare after complete subsidisation of the perineal swelling i.e. a gap of 15 days after foaling. After a gap of 15 days of foaling the perineal swelling was completely subsided and the mares were again brought to the Teaching Veterinary Clinical Complex. The mares were controlled in standing position in travis. The mares were sedated with xylazine $(5-10 \mathrm{ml}$, slow i.v. route). Caudal block was achieved by administrating $5-10 \mathrm{ml}$ lignocaine $\mathrm{Hcl}$ in $1^{\text {st }} \& 2^{\text {nd }}$ intra-coccygeal space. The perineal area was prepared for surgery. The ventral wall of the rectum and dorsum of the vagina were separated so that separate shelf for rectum \& vagina can be prepared (Figure 2).

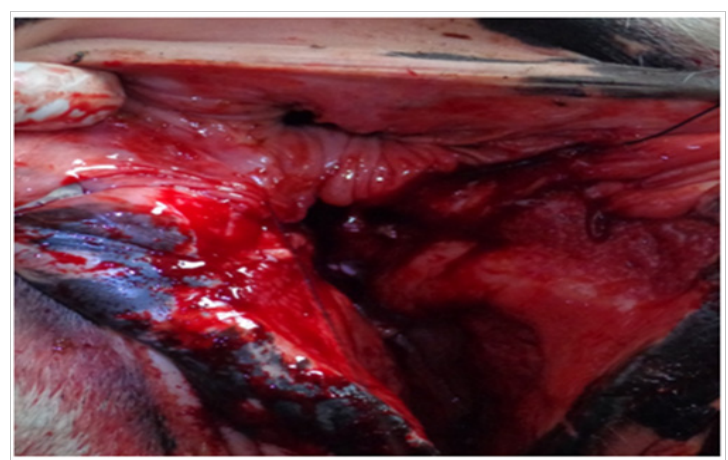

Figure 2 Showing separate shelf for rectum \& vagina.

After making shelves for rectum \& vagina, the teared rectum and vagina were sutured by six bite techniques using silk No.3. When the sutures were tightened then there was separate passage for rectum \& vagina. The teared lips of vagina were closed by Caslick's sutures and there was no problem of pneumo-vagina (Figure 3).

Postoperatively, the mares were maintained on antibiotics, antihistaminics, anti-inflammatory, vitamin- C \& B-complex for another 10Days. The repaired perineal area was dressed with light povidoneiodine solution followed by maggicidal spray for 14days. The mares were maintained on green grass only to pass loose faeces and to avoid any straining. 


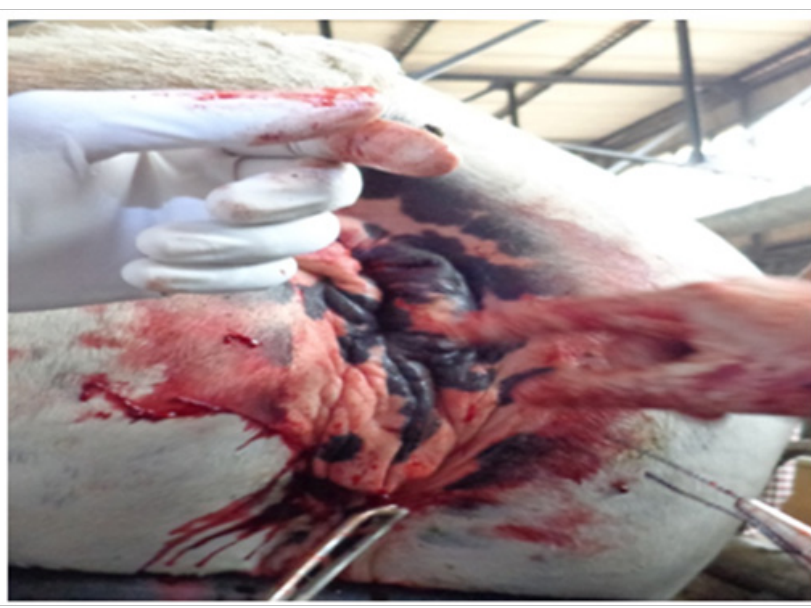

Figure 3 Showing suturing of rectum \& vagina and caslick operation.

\section{Results}

The mares started passing urine and faeces through the separate openings after repair. There was little swelling at the site of surgery which got subsided after 7days of surgery. Three mares showed uneventful recovery after 14 days of surgery. On $14^{\text {th }}$ day of surgery in two mares there was swelling at the site of surgery though the mares were voiding faeces through the anal opening. In these mares there was partial disruption of the surgical wound. In these mares the surgical wounds were dressed daily and allowed to heal without any surgical intervention. The surgical wound showed tendency of healing and got healed completely after another 14days. Three mares where recovery was uneventful showed signs of oestrus and got conceived after covering. In two mares there was history of repeat breeding. The mares were treated for repeat breeding. ${ }^{1,2}$

\section{Discussion}

Perineal laceration is a serious complication in unattended mares during foaling and is very difficult to manage also. At the site of laceration there is usually contamination, inflammation and oedema. Adams and Fessler, 2000 also observed such complications of laceration. To check these complications a course of antibiotics, anti-histaminics, anti-inflammatory, vitamin-C \& B-complex is given. The surgical intervention is usually successful when inflammation and oedema get subsided therefore the cases of perineal lacerations are attempted after 14-20days of laceration. Similar observations were also made by Desjardins et al. ${ }^{2}$ Six bite techniques are found to be successful method for repair of perineal laceration. Caslick's operation was useful to prevent pneumovagina. After repair the mares are again maintained on full course of antibiotics, anti-histaminics, anti-inflammatory, vitamin- C \& B-complex. The repaired perineal area should be dressed daily with light povidone-iodine solution followed by maggicidal spray. The mares should also be maintained on green grass only to pass loose faeces and to avoid any straining. Kersjes et al. ${ }^{3}$ also stressed use of green grass to pass loose faeces and to avoid tension on sutures. After two weeks, three mares showed complete recovery while in two mares there was infection and partial dehiscence of surgical wound which got healed after daily anti septic dressing.

\section{Acknowledgements}

None.

\section{Conflict of interest}

The author declares no conflict of interest.

\section{References}

1. Adams SB, Fessler JF. Third-degree perineal laceration repair. In: Adams $\mathrm{SB}$, et al. editors. Atlas of equine surgery. 1st ed. Philadelphia, WB Saunders Co; 2000. p. 241-244.

2. Desjardins MR, Trout DR, Little CB. Surgical repair of rectovaginal fistulae: twelve cases (1983-1991). Can Vet J. 1993;34(4):226-231.

3. Kersjes AW, Nemeth F, Rutgers JE. Perineal reconstruction after third degree lacerations. In: Kersjes AW, et al. editors. A colour atlas of large animal surgery Utrecht. 1st ed. Wolf Medical Publications Ltd; 1986. p. $80-81$. 